Revista Brasileira de Agricultura Irrigada v.12, nº.3, p. 2613 - 2620, 2018

ISSN 1982-7679 (On-line)

Fortaleza, CE, INOVAGRI - http://www.inovagri.org.br

DOI: $10.7127 /$ rbai.v12n300733

Protocolo 733.18 - 20/09/2017 Aprovado em 22/05/2018

\title{
QUALIDADE DA ÁGUA PARA IRRIGAÇÃO NA COMUNIDADE QUILOMBOLA VÃO GRANDE, MUNICÍPIO DE BARRA DO BUGRES/MT
}

\author{
Tadeu Miranda de Queiroz ${ }^{1}$, Martins Toledo de Melo², Fernanda da Silva Ferreira ${ }^{3}$
}

\begin{abstract}
RESUMO
A irrigação é uma tecnologia que permite a produção na entressafra, previne danos causados pelo déficit hídrico natural, aumenta a produtividade e agrega valor à produção, entre outras vantagens. No entanto, carece de planejamento e estudos de qualidade, sendo que a má qualidade pode inviabilizar a agricultura irrigada. Neste contexto, objetivou-se neste trabalho, avaliar algumas variáveis de expressam a qualidade da água para irrigação na localidade assentamento remanescente quilombola Vão Grande, no município de Barra do Bugres/MT. O estudo avaliou a concentração de Sódio, Cálcio, Magnésio, Cloretos, Ferro, Potássio, o pH e a Condutividade Elétrica, bem como a Temperatura da água na fonte e Razão de Adsorção de Sódio. Os valores encontrados foram comparados com parâmetros definidos na literatura específica. Os resultados mostraram que apenas a temperatura atingiu valores acima do desejado. As demais variáveis, quando analisadas isoladamente, não atingiram os limites de alarme. Em conjunto, a RAS e CE, apontaram para o potencial risco de sodicidade podendo, com o tempo, comprometer significativamente o regime de infiltração de água no solo. Concluise, no contexto geral, que as águas superficiais das fontes avaliadas são adequadas para irrigação, considerando as variáveis estudadas e o período de realização da pesquisa.
\end{abstract}

Palavras-Chave: planejamento, agricultura familiar, desenvolvimento regional

\section{QUALITY OF WATER FOR IRRIGATION IN THE QUILOMBO COMMUNITY VÃO GRANDE, MUNICIPALITY OF BARRA DO BUGRES / MT}

\footnotetext{
ABSTRACT

The irrigation is a technology that allows production in the off season, prevents damage caused by natural water deficit, increases productivity and adds value to production, among other advantages. However, it lacks quality planning and studies, and poor quality can make irrigated

${ }^{1}$ Professor do Departamento Eng. Produção Agroindustrial, Universidade do Estado de Mato Grosso UNEMAT, Rua A, s/nº Cohab São Raimundo, Barra do Bugres/MT. E-mail: tdmqueiroz@unemat.br.

${ }^{2}$ Técnico de Indigenismo, Servidor da FUNAI, Mestrando do Programa de Pós Graduação em Ambiente e Sistemas de Produção Agrícola - UNEMAT. E-mail: toledo_martins@hotmail.com

${ }^{3}$ Professora do Departamento de Agronomia da Universidade do Estado de Mato Grosso, Nova Mutum. E-mail: fernanda.agronomiaunemat@hotmail.com
} 
agriculture unfeasible. In this context, the objective of this study was to evaluate some variables that express water quality for irrigation in the remaning quilombo settlement Vão Grande, in Barra do Bugres/MT. The study evaluated the concentration of Sodium, Calcium, Magnesium, Chlorides, Iron, Potassium, $\mathrm{pH}$ and Electrical Conductivity, as well as Water Temperature at source and Sodium Adsorption Ratio. The values found were compared with parameters defined in the specific literature. The results showed that only the temperature reached values higher than desired. The other variables, when analyzed separately, did not reach the alarm limits. Together, the RAS and CE, pointed to the potential risk of sodicity and might, over time, significantly compromise the water infiltration regime in the soil. It is concluded, in the general context, that the surface waters of the evaluated sources are suitable for irrigation.

Keywords: Planning, family agriculture, regional development

\section{INTRODUÇÃO}

A região do assentamento Vão Grande é ocupada por pequenos lotes de remanescentes quilombolas onde se pratica a agropecuária familiar e de subsistência. A produção é diversificada entre criação de gado para corte e leite, suínos e aves caipiras, cultivos de banana, mandioca, abacaxi e citros, milho, arroz, feijão e hortaliças de modo geral, entre outros. Alguns poucos produtores vendem 0 excedente da produção na feira livre de Barra do Bugres.

Todas as atividades são desenvolvidas de modo artesanal, com pouco investimento em tecnologia, e baixo emprego de maquinaria agrícola, havendo ainda, sistemas de cultivo primitivo com uso de roçada, ateio de fogo e destoca, com semeadura, tratos culturais e colheita manual.

A inserção da Universidade do Estado de Mato Grosso na Comunidade Vão Grande busca aprimorar os meios de produção e orientar a população para a adoção de novas tecnologias. A agricultura praticada no local é bastante afetada pelo déficit hídrico no período de estiagem, sendo que a irrigação pode ser uma alternativa para viabilizar a produção durante todo o ano e assim, melhorar a qualidade e quantidade da oferta de alimentos e ainda garantir excedente para o comércio local como forma de complementação de renda.

Todavia, os empreendimentos de irrigação demandam estudos preliminares de caracterização da água definindo a sua aplicabilidade e orientando a escolha do método, sistema de aplicação e manejo.
Para caracterização da água de irrigação Almeida (2010) recomenda análises detalhadas em coletas mensais, pelo menos durante um ano, e depois uma coleta antes e outra depois do período chuvoso. No entanto, o mesmo autor relata que a frequência de amostragem depende da disponibilidade de recursos materiais e humanos e facilidade de acesso aos laboratórios, entre outros fatores.

Na região do Vão Grande este estudo é inédito, portanto, mesmo que preliminar, é fundamental para nortear políticas públicas e planejamento dos moradores, além de representar uma relevante contribuição para o conhecimento técnico científico dessa importante microrregião. Neste sentindo, objetivou-se com este trabalho avaliar a qualidade da água de fontes superficiais para irrigação no Assentamento de remanescentes Quilombolas, na região do Vão Grande, município de Barra do Bugres/MT.

\section{MATERIAL E MÉTODOS}

A fase analítica do presente trabalho foi realizada no Laboratório de Qualidade de Água (LaQuA) da Universidade do Estado de Mato Grosso (UNEMAT), no Campus "Deputado Estadual René Barbour” no município de Barra do Bugres, Mato Grosso, exceto para as variáveis sódio, potássio e ferro, as quais foram determinadas em laboratório particular certificado.

As análises de água foram feitas a partir de amostras tomadas em 9 fontes de água superficial que atendem às Comunidades de 

MUNICÍPIO DE BARRA DO BUGRES/MT

Baixius e Morro Redondo na Localidade Assentamento Remanescente Quilombola Vão Grande, no município de Barra do Bugres, estado de Mato Grosso, Mesorregião do sudoeste mato-grossense e micro região de Tangará da Serra, na transição cerrado/amazônia.

O clima local é tropical do tipo Aw conforme classificação de Köppen, com duas estações bem definidas, uma seca de maio a setembro e outra úmida ou chuvosa que vai de outubro a abril. A temperatura média para a região é de $24,0{ }^{\circ} \mathrm{C}$ e o regime pluviométrico anual acumula $1500 \mathrm{~mm}$, conforme Dallacort et al. (2010).

O solo da região do Vão Grande, entre a bordadura da Serra das Araras e o Rio Jauquara, é mesclado de Argissolo Vermelho Amarelo Distrófico, Neossolo Litólico Distrófico e Cambissolo Háplico Distrófico com topografia variando de suave ondulado a ondulada (IBGE, 2011). Visualmente no local, observa-se solo arenoso e pedregoso, pobre e de relevo montanhoso com pequenas planícies nas encostas dos morros e margem dos cursos de água, com vegetação típica de cerrado ralo a médio. Essas planícies sustentam o sistema produtivo agropecuário das comunidades locais.

Na região ocorrem nascentes e pequenos córregos e o Rio Jauquara, afluente do Rio Paraguai, principal formador do pantanal. O estudo privilegiou as fontes de água que já contam com algum sistema de bombeamento ou de condução por gravidade para abastecimento das comunidades, não incluindo o Rio Jauquara.

Para transporte das amostras de água foram utilizados frascos de plástico com capacidade de $1 \mathrm{~L}$, os quais foram lavados com água corrente e sabão, depois com água destilada e por fim secos. Os mesmos possuem tampa rosqueável que garantiu o seu fechamento hermético evitando vazamentos e possível contaminação.

A coleta de amostras de água, em cada fonte, foi realizada entre 15 de julho de 2013 e 14 de janeiro de 2014, com frequência mensal. No ato da coleta cada frasco foi lavado três vezes com água da própria fonte e em seguida preenchidos com água até a boca não restando ar livre dentro do mesmo, fechados e acondicionados em caixa térmica com gelo até a condução ao laboratório. As amostras foram analisadas, em triplicada, em no máximo 24 horas após a coleta (Mantovani, et al., 2009; Almeida, 2010). Todos os procedimentos analíticos foram feitos em atendimento aos métodos descritos no Standard Methods for Examination of Water and Wastewater (APHA, 2005).

Os procedimentos das análises e equipamentos utilizados estão resumidos no Quadro 1, bem como o período de análise de cada variável em função da disponibilidade de recursos e equipamentos.

Quadro 1. Descrição dos métodos, equipamentos utilizados nas análises e período de análise de cada variável.

\begin{tabular}{|l|l|c|}
\hline \multicolumn{1}{|c|}{ Variável } & \multicolumn{1}{c|}{ Método/Equipamento } & \multicolumn{1}{c|}{ Período de Análise } \\
\hline Cálcio & Titulação com EDTA 0,01 mol L ${ }^{-1}$ & $15 / 12 / 2013$ a 16/04/2014 \\
\hline Magnésio & Titulação com EDTA 0,01 mol L ${ }^{-1}$ & $15 / 12 / 2013$ a $16 / 04 / 2014$ \\
\hline Cloretos & Titulação com Nitrato de Prata 0,01 M & $14 / 01 / 2013$ a 16/04/2014 \\
\hline Condutividade Elétrica & Condutivímetro de Bancada - DM31 & $09 / 11 / 2013$ a 16/04/2014 \\
\hline pH & pHmetro de bancada Marconi PA200 & $15 / 07 / 2013$ a 16/04/2014 \\
\hline Temperatura & Termômetro de mercúrio 0 a 60 ${ }^{\circ} \mathrm{C}$ & $15 / 07 / 2013$ a 16/04/2014 \\
\hline Turbidez & Turbidímetro de bancada & $15 / 07 / 2013$ a 16/04/2014 \\
\hline Ferro & Espectrofotometria & $15 / 12 / 2013$ a $16 / 04 / 2014$ \\
\hline Sódio & Espectroscopia de Emissão Atômica & $15 / 12 / 2013$ a $16 / 04 / 2014$ \\
\hline Potássio & Espectroscopia de Emissão Atômica & $15 / 12 / 2013$ a 16/04/2014 \\
\hline RAS & Relação entre Sódio e Cálcio+Magnésio & $15 / 12 / 2013$ a 16/04/2014 \\
\hline
\end{tabular}


Por indisponibilidade de equipamento apropriado nas instalações do Campus de Barra do Bugres as análises de Ferro, Sódio e Potássio foram realizados em Laboratório particular certificado, localizado na Capital Cuiabá (180 $\mathrm{km})$. A concentração dos íons foi determinada em mg $\mathrm{L}^{-1}$ e posteriormente convertida para mmolc $_{\mathrm{c}} \mathrm{L}^{-1}$, exceto para o Ferro, uma vez que o mesmo pode estar presente na água em diversas formas iônicas.

Moruzzi e Reali (2012) relatam que o ferro em águas naturais de baixo $\mathrm{pH}$ apresentam-se na forma reduzida $\left(\mathrm{Fe}^{+2}\right)$ ou $\left(\mathrm{FeOH}^{+}\right)$, o que ocorre principalmente em águas subterrâneas. Quando em contato com o oxigênio e/ou cloro, o ferro das águas superficiais, geralmente apresenta-se na forma $\mathrm{Fe}^{+3}$. Por isso, é comum determinar nas análises o ferro total e expressá-lo em $\mathrm{mg} \mathrm{L}^{-1}$, o que foi feito neste trabalho, embora o Laboratório tenha utilizado na calibração do equipamento uma solução padrão de ferro na forma $\mathrm{Fe}^{+3}$.

A RAS foi calculada (Eq.01) com os dados de $\mathrm{Ca}^{+2}, \mathrm{Mg}^{+2}$ e Na ${ }^{+}$transformados de $\mathrm{mg}$ $\mathrm{L}^{-1}$ para meq $\mathrm{L}^{-1}$ que é numericamente igual a $\operatorname{mmol}_{\mathrm{c}} \mathrm{L}^{-1}$.

$$
R A S=\frac{N a^{+}}{\sqrt{\frac{C a^{+2}+M g^{+2}}{2}}} \quad \text { eq.01 }
$$

Em que:

RAS é a Razão de Adsorção de Sódio, $\left(\right.$ mmol $_{\mathrm{c}}$ $\left.\mathrm{L}^{-1}\right)^{0,5}$;

$\mathrm{Na}^{+}$é a concentração de sódio, meq $\mathrm{L}^{-1}$;

$\mathrm{Ca}^{+2}$ é a concentração de cálcio, meq $\mathrm{L}^{-1}$;

$\mathrm{Mg}^{+2}$ é a concentração de magnésio, meq $\mathrm{L}^{-1}$;

Os dados, para cada variável, foram apresentados e descritos pela média, desvio padrão, máximo e mínimo.

\section{RESULTADOS E DISCUSSÃO}

Os resultados para cada variável e para cada ponto estão apresentados na Tabela 1, onde se pode observar também a média, o desvio padrão e os valores máximos e mínimos para cada variável, considerando os resultados individuais para os 9 pontos analisados neste estudo. De modo geral, a água em todos os pontos atende aos limites considerados adequados para irrigação. Destaca-se que para avaliação da Turbidez utilizou-se como parâmetro o limite citado na Resolução $\mathrm{N}^{\circ}$ 357/2005 do Conselho Nacional de Meio Ambiente para corpos d'água Classe 1, a qual pontua que um dos usos possíveis para esse tipo de água é a irrigação, todavia não trata-se de uma diretriz para irrigação, mas serve de referência.

Tabela 1. Estatística descritiva da qualidade da água da Localidade Remanescente Quilombola Vão Grande, Município de Barra do Bugres no estado de Mato Grosso.

\begin{tabular}{|c|c|c|c|c|c|c|c|c|c|c|c|}
\hline \multirow{2}{*}{ Pontos } & $\mathrm{Na}^{+}$ & $\mathrm{Ca}^{+2}$ & $\mathrm{Mg}^{+2}$ & $\mathrm{Cl}^{-}$ & $\mathrm{K}^{+}$ & \multirow{2}{*}{$\begin{array}{c}\mathrm{Fe} \\
\mathrm{mg} \mathrm{L}^{-1}\end{array}$} & \multirow{2}{*}{$\begin{array}{c}\mathrm{CE} \\
\mathrm{dS} \mathrm{m}^{-1}\end{array}$} & \multirow{2}{*}{$\begin{array}{c}\text { Tur } \\
\text { NTU }\end{array}$} & \multirow{2}{*}{$\begin{array}{c}\mathrm{T} \\
{ }^{\circ} \mathrm{C}\end{array}$} & \multirow{2}{*}{ RAS } & \multirow{2}{*}{$\mathrm{pH}$} \\
\hline & \multicolumn{5}{|c|}{$\mathrm{mmol}_{\mathrm{C}} \mathrm{L}^{-1}$} & & & & & & \\
\hline P1 & 0,012 & 0,17 & 0,13 & 0,08 & 0,017 & 0,139 & 0,06 & 27,69 & 27,43 & 0,50 & 6,00 \\
\hline P2 & 0,002 & 0,22 & 0,23 & 0,07 & 0,009 & 0,091 & 0,09 & 70,63 & 27,00 & 0,11 & 6,33 \\
\hline P3 & 0,004 & 0,13 & 0,09 & 0,09 & 0,005 & 0,043 & 0,04 & 20,72 & 35,86 & 0,21 & 6,70 \\
\hline P4 & 0,012 & 0,24 & 0,22 & 0,07 & 0,016 & 0,574 & 0,09 & 45,15 & 30,00 & 0,62 & 6,53 \\
\hline P5 & 0,001 & 0,09 & 0,12 & 0,09 & 0,005 & 0,045 & 0,05 & 21,28 & 28,14 & 0,10 & 6,76 \\
\hline P6 & 0,004 & 0,06 & 0,13 & 0,08 & 0,004 & 0,057 & 0,01 & 19,95 & 27,21 & 0,25 & 7,17 \\
\hline P7 & 0,002 & 0,16 & 0,15 & 0,11 & 0,004 & 0,012 & 0,06 & 51,73 & 29,86 & 0,09 & 6,65 \\
\hline P8 & 0,003 & 0,16 & 0,15 & 0,08 & 0,006 & 0,169 & 0,05 & 45,74 & 26,79 & 0,20 & 6,64 \\
\hline P9 & 0,000 & 0,25 & 0,16 & 0,07 & 0,001 & 0,001 & 0,05 & 55,52 & 28,14 & 0,02 & 6,59 \\
\hline Média & 0,004 & 0,164 & 0,153 & 0,081 & 0,008 & 0,126 & 0,054 & 39,82 & 28,94 & 0,23 & 6,60 \\
\hline Desv. Pad. & 0,004 & 0,064 & 0,045 & 0,012 & 0,006 & 0,177 & 0,023 & 18,21 & 2,84 & 0,20 & 0,32 \\
\hline Máximo & 0,012 & 0,245 & 0,227 & 0,105 & 0,017 & 0,574 & 0,082 & 70,63 & 35,86 & 0,62 & 7,17 \\
\hline Mínimo & 0,000 & 0,058 & 0,093 & 0,067 & 0,001 & 0,0010 & 0,008 & 19,95 & 26,79 & 0,02 & 6,00 \\
\hline
\end{tabular}




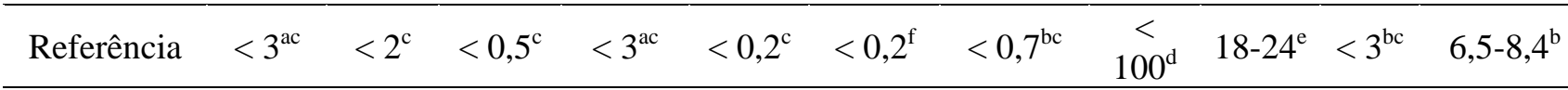

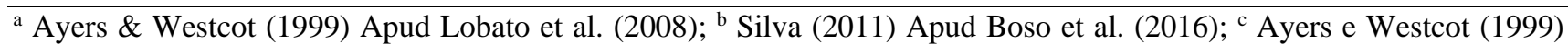

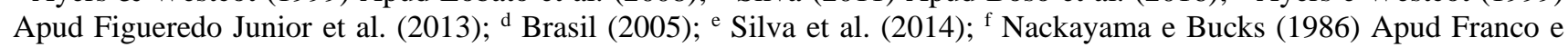
Hernandez (2009).

Os valores de sódio e cloro, quando analisados isoladamente, não apresentaram restrição para uso na irrigação indicando boa qualidade da água. Os valores encontrados são próximos de zero para as duas variáveis, valores esses muito inferiores aos mensurados por Lobato et al. (2008) em estudo realizado no Distrito Irrigado Baixo Acaraú no Ceará. Embora a presente citação reporte região geográfica bastante distinta, a comparação ilustra a possibilidade real de implantação de sistemas de irrigação com uso das águas superficiais da região do Vão Grande.

Por outro lado Barroso et al. (2010) estudando águas subterrâneas para irrigação na região do Baixo Jaguaribe, no Ceará, encontraram valores de Sódio entre 8,03 e 9,03 $\operatorname{mmol}_{\mathrm{c}} \mathrm{L}^{1}$, na época seca. Os autores relataram o efeito da escassez de chuva na concentração salina no lençol freático e enfatizaram a necessidade de cautela no uso dessas águas, recomendando que os irrigantes devam priorizar o cultivos de espécies adaptadas ou tolerantes, ressalva esta que vale para a região do Vão Grande.

Os valores de Cálcio oscilaram entre 0,058 e 0,245 mmolc $_{c} L^{-1}$ e os valores de magnésio ficaram entre 0,093 e $0,227 \mathrm{mmol}_{\mathrm{c}} \mathrm{L}^{-}$ 1, ambos abaixo dos valores máximos de referência reportados pela literatura específica, o que indica total normalidade e nenhum risco para as culturas irrigadas com essas águas superficiais.

BLUMBERG e AZEVEDO NETO (1956) citam que as águas naturais possuem relação $\mathrm{Mg}: \mathrm{Ca}$ da ordem de 1:5 a 1:20. No presente estudo encontrou-se relação $\mathrm{Mg}: \mathrm{Ca}$ variando entre 1:0,62 a 1:1,07 para as concentrações máxima e mínima, respetivamente. Nota-se equilíbrio entre os íons com relação $\mathrm{Mg}$ :Ca tendendo a 1:1, o que não chega a ser um problema uma vez que ambos são encontrados em concentrações muito baixas. Porém, é importante observar também a concentração desses elementos no solo ao mesmo tempo em que se atente a possíveis sintomas de toxidez por magnésio nas plantas irrigadas.

Quando os resultados são comparados com outros estudos para a mesma finalidade observa-se concordância. Por exemplo, Lopes et al. (2014), em estudo da água do reservatório Orós no Ceará, encontraram concentrações de Cálcio variando de 1,12 a 3,01 mmolc $\mathrm{L}^{-1}$ e de magnésio entre 0,23 a $1,71 \mathrm{mmol}_{\mathrm{c}} \mathrm{L}^{-1}$. Já Figueredo Junior et al. (2013) em estudo da qualidade das águas do Rio Parnaíba no perímetro irrigado Tabuleiros Litorâneas do Piaui, encontraram valores de Cálcio entre 0,33 e $0,82 \mathrm{mmol}_{\mathrm{c}} \mathrm{L}^{-1}$ e de Magnésio entre 0,23 e $0,57 \mathrm{mmol}_{\mathrm{c}} \mathrm{L}^{-1}$.

Silva et al. (2011) relatam que o ferro, acompanhado do manganês e de altas concentrações de sólidos solúveis, são os principais inimigos dos emissores e tubulações, em especial nos sistemas de irrigação localizados.

Os valores de ferro total nas águas das fontes avaliadas ficaram entre 0,008 e $0,082 \mathrm{mg}$ $\mathrm{L}^{-1}$, indicando baixo potencial de dano ao sistema de irrigação por micro aspersão ou gotejamento $\left(\mathrm{Fe}<0,2 \mathrm{mg} \mathrm{L}^{-1}\right)$. Na irrigação por aspersão o ferro não chega a ser problema uma vez que os orifícios dos bicos de aspersão são de dimensões tais que dificultam a obstrução por incrustações ferruginosas.

Franco e Hernandez (2009) avaliando a qualidade físico-química da água utilizada para irrigação na micro bacia hidrográfica do Rio Coqueiro no estado de São Paulo, encontraram valores de ferro entre 0,2 e $5,0 \mathrm{mg} \mathrm{L}^{-1}$ com médio a alto potencial de dano à operação dos sistemas de irrigação.

Souza et al. (2008) em caracterização das águas do Vale do Açú no Rio Grande do Norte, observaram valores de potássio entre 0,177 e $0,243 \mathrm{mg} \mathrm{L}^{-1}$, equivalente a 0,005 e 0,006 mmolc $_{c} \mathrm{~L}^{-1}$, respectivamente. Valores esses 
muito inferiores aos que foram encontrados nas águas superficiais do Vão Grande (0,001 $\left.0,017 \mathrm{mmol}_{\mathrm{c}} \mathrm{L}^{-1}\right)$. O Potássio, à semelhança do Cálcio e Magnésio, também é um macro nutriente para as culturas, portanto sua presença é benéfica, embora possa tornar-se um agravante em concentrações superiores a 0,2 mmolc L ${ }^{-1}$ (Figueredo Junior et al., 2013).

Por ser um íon, o potássio, pode contribuir para a salinidade (Silva et al., 2011), porém não de forma expressiva devido à sua baixa concentração na água. A Companhia Ambiental do Estado de São Paulo (CETESB, 2009), no relatório de qualidade das águas interiores no estado de São Paulo reporta a valores de potássio inferiores a $10 \mathrm{mg} \mathrm{L}^{-1}(0,25$ $\mathrm{cmol}_{c} \mathrm{~L}^{-1}$ ) em águas superficiais. Por essa referência observa-se que a concentração de potássio nas águas superficiais avaliadas é muito inferior ao valor considerado normal.

$\mathrm{Na}$ água das fontes estudadas a CE foi de $0,054 \pm 0,023 \mathrm{dS} \mathrm{m}^{-1}$, valor que é considerado baixo pois aceita-se como ideal para irrigação águas com CE de até 3,0 dS m${ }^{-1}$.

Em estudo da caracterização da qualidade fisico-química da água para irrigação em diferentes aquíferos na área sedimentar do estado do Rio Grande do Norte, Oliveira e Maia (1998) encontram CE variando entre 0,8 e 4,0 $\mathrm{dS} \mathrm{m}^{-1}$. Os autores relataram enquadramento desses resultados com os limites considerados normais para irrigação.

$\mathrm{O} \mathrm{pH}$ médio das fontes analisadas está dentro da faixa considerada ideal, embora próximo do limite inferior. Apenas dois pontos (P1 e P2) apresentaram $\mathrm{pH}$ ligeiramente inferior ao mínimo desejável para irrigação (6,50). Em estudo realizado em Salto do Lontra/PR, Reis et al. (2011) encontraram pH entre 6,9 e 7,7 e Silva et al. (2014) avaliando a qualidade da água de uma barragem que abastece um pivô central em Goiânia/Go, encontraram pH entre 6,78 e 6,97. Esses resultados evidenciam que as águas superficiais da Localidade Vão Grande assemelham-se a outras fontes já utilizadas para irrigação, o que revela total possibilidade de utilização dessas águas para irrigação.

Melo et al. (2009) Apud Silva et al. (2014) relatam que a temperatura da água de irrigação não deve extrapolar a faixa de 18 e 24
${ }^{\circ} \mathrm{C}$ sob pena de prejudicar a absorção de nutrientes pelas plantas. No presente estudo encontraram-se temperaturas entre 26,79 e $35,80^{\circ} \mathrm{C}$, valores estes que não estão dentro da faixa considerada normal conforme os autores supracitados. Esses valores mais elevados da temperatura da água não significam impedimento à irrigação, mas apenas atenção aos possíveis efeitos nas culturas. Uma alternativa que poderá minimizar esses efeitos é fazer a irrigação nos horários de temperatura mais amena, por exemplo, à noite.

A Resolução No 357/2005 do Conselho Nacional de Meio Ambiente - CONAMA (Brasil, 2005) limita a Turbidez das águas aplicáveis à irrigação em 100 NTU. Nas águas superficiais das fontes analisadas encontraramse valores entre 19,95 e 70,63 NTU, portanto abaixo do máximo de referência. Esse resultado aponta para boa qualidade da água em relação a essa variável. Neste caso, deve se ter atenção ao uso de sistemas de filtração eficientes principalmente se desejar utilizar irrigação localizada por gotejamento.

Cálcio e Magnésio são macro nutrientes fundamentais para o desenvolvimento das culturas agrícolas. Os valores encontrados nas águas de irrigação são insuficiente para representar contribuição expressiva desses elementos na nutrição das plantas e muito longe de representarem qualquer problema de toxidade. A concentração desses íons ganha importância quando combinada com o Sódio, efeito esse expresso pela Razão de Adsorção de Sódio.

Conforme dados da Tabela 1 observa-se que não há risco de salinização do solo pela água das fontes analisadas, onde todos os pontos enquadraram-se na Classe $\mathrm{C} 1$, ou seja, sem risco de salinização.

Embora tanto a RAS quanto CE estejam baixos, o seus efeitos combinados revelam severos problemas de sodicidade em todos os pontos, Classe S3 (Almeida, 2010). Esse resultado aponta para o risco de redução da infiltração da água no solo, comprometendo a irrigação e o desenvolvimento das plantas.

\section{CONCLUSÕES}




\section{QUALIDADE DA ÁGUA PARA IRRIGAÇÃO NA COMUNIDADE QUILOMBOLA VÃO GRANDE, MUNICÍPIO DE BARRA DO BUGRES/MT}

Isoladamente as variáveis avaliadas não revelaram impedimento ao uso da água para irrigação nas fontes analisadas, embora a temperatura medida na fonte tenha sido, em média, maior do que o desejado, o que não chega a ser um entrave pois pode se programar a aplicação de água às culturas nos horários mais frescos, por exemplo à noite.

As fontes enquadraram-se na classe $\mathrm{C} 1$ de salinidade indicando que não há risco de salinização do solo, porém quando combinadas, a RAS e CE apontaram para risco severo de sodicidade (Classe S3) indicando risco de redução da infiltração de água no solo.

\section{AGRADECIMENTO}

À Fundação de Amparo à Pesquisa do Estado de Mato Grosso (FAPEMAT), pelo financiamento da pesquisa (Edital $\mathrm{N}^{\circ}$ 004/2011; Processo: No. 346077/2011).

\section{LITERATURA CITADA}

ALMEIDA, O. A de. Qualidade da Água de Irrigação. Cruz das Almas: Embrapa Mandioca e Fruticultura, 2010. 227p.

APHA - American Public Health Association; American Water Works Association - AWWA; Water Environment Federation - WEF. Standard methods for the examination of water and wastewater. 21 st Ed. Washington, DC, 2005.

AYERS, R.S.; WESTCOT, D.W. A qualidade da água na agricultura. Estudos FAO. Irrigação e Drenagem 29 (Revisado). Campina Grande - PB UFPB. trad: GHEYI, H.R.; MEDEIROS, J.F.; DAMASCENO, F.A.V. 1991, 218 p.

BARROSO, A. A. F.; NESS, R. L. L.; GOMES FILHO, R. R.; SILVA, F. L.; CHAVES, M. J. L.; LIMA, C. A. Avaliação qualitativa das águas subterrâneas para irrigação na região do Baixo Jaguaribe - Ceará. Revista Brasileira de
Agricultura Irrigada, v.4, n.3, p.150-155, 2010.

BLUMBERG, E; AZEVEDO NETO, J.M. Alcalinidade e dureza das águas naturais. Revista DAE, v.28, n.1033, p.63-79, 1956.

BOSO, A. C. M. R.; GABRIEL, C. P. C.; PIAZENTIN, J. C. Análise dos parâmetros da qualidade da água destinada a irrigação. Fórum Ambiental da Alta Paulista, v.12, n.6, p.1-8, 2016.

BRASIL. Ministério do Meio-Ambiente. Conselho Nacional do Meio Ambiente. Resolução n.357, de 17 de março de 2005. Disponível em: http://www.mma.gov.br/port/conama/res/res05 /res35705.pdf. Acesso em: 24/05/2016.

CETESB COMPANHIA AMBIENTAL DO ESTADO DE SÃO PAULO. Qualidade das águas interiores no estado de São Paulo. São Paulo, CETESB, 44p., 2009.

DALLACORT, R.; MOREIRA, P. S. P.; INOUE, M. H.; SILVA, D. J.; CARVALHO, I. F.; SANTOS, C. Wind speed and direction characterization in Tangará da Serra, Mato Grosso State, Brazil. Revista Brasileira de Meteorologia, v. 25, n. 3, p.359-364, 2010.

FRANCO, R. A. M.; HERNANDEZ, F. B. T. Qualidade da água para irrigação na microbacia do Coqueiro, Estado de São Paulo. Revista Brasileira de Engenharia Agrícola e Ambiental, v.13, n.6, p.772-780, 2009.

FIGUEREDO JÚNIOR, L. G. M.; FERREIRA, J. R.; FERNANDES, C. N. V.; ANDRADE, A. C.; AZEVEDO, B. M.; SARAIVA, K. R. Avaliação da qualidade da água do distrito de irrigação Tabuleiros Litorâneos do Piauí DITALPI. Revista Brasileira de Agricultura Irrigada, v.7, n.3, p.213-223, 2013.

IBGE. Instituto Brasileiro de Geografia e Estatística. Embrapa. Mapa de Solos do 
Brasil. Rio de Janeiro; IBGE, 2011. Escala 1:5.000.000.

LOBATO, F. A. O.; ANDRADE, E. M.; MEIRELES, A. C. M.; CRISOSTOMO, L. A. Sazonalidade na qualidade da água de irrigação do Distrito Irrigado Baixo Acaraú, Ceará. Revista Ciência Agronômica, Fortaleza, v.39, n.1, p.167-172, Jan.- Mar., 2008.

LOPES, F. B.; ANDRANDE, E. M.; MEIRELES, A. C. M.; BECKER, H.; BATISTA, A. A. Assessment of the water quality in a large reservoir in semiarid region of Brazil. Revista Brasileira de Engenharia Agrícola e Ambiental. v.18, n.4, p.437-445, 2014.

MANTOVANI, E. C.; BERNARDO, S.; PALARETTI, L. F. Irrigação: princípios e métodos. $3^{a}$ Edição. Viçosa: Editora UFV, 2009. 355p.

MORUZZI, R. B.; REALI, M. A. P. Oxidação e remoção de Ferro e Manganês em águas para fins de abastecimento público ou industrial - uma abordagem geral. Revista de Engenharia e Tecnologia, v.4, n.1, Abr/2012.

OLIVEIRA, M.; MAIA, C. Qualidade fisicoquímica da água para irrigação em diferentes aquíferos na área sedimentar do estado do Rio Grande do Norte. Revista Brasileira de Engenharia Agrícola e Ambiental, Campina Grande, v.2, p.17-21, 1998.
REIS, C. F.; VILAS BOAS, M. A.; MERCANTE, E.; HERMES, E.; REISDORFER, M. Avaliação da qualidade da água para irrigação em Salto do Lontra - PR. Engenharia Ambiental - Espírito Santo do Pinhal, v.8, n.1, p.069-078, jan./mar, 2011.

SHAPIRO, S. S.; WILK, M. B. An analysis of variance test for normality (complete samples). Biometrika, Oxford, v.52, n.3/4, p.591-611, dez. 1965.

SILVA, I. N.; FONTES, L. O.; TAVELLA, L. B.; OLIVEIRA, J. B.; OLIVEIRA, A. C. Qualidade da água na irrigação. Agropecuária Científica no Semi-Árido, v.7, n.3, p.01-15, julho/setembro, 2011.

SILVA, L. R.; CUNHA, A. H. N.; SILVA, S. M. C.; SOUZA, J. M. F. Avaliação de parâmetros físico-químicos da água de irrigação utilizada em um pivô central em Goiânia - GO. Global Science Technology, Rio Verde, v.7, n.3, p.96-102, set/dez, 2014.

SOUSA, R. A.; FILHO, J. A.; MENEZES, V. C. L. Caracterização qualitativa das águas da microrregião do Vale do Açu-RN. Revista Brasileira de Agricultura Irrigada, v.2, n.1, p.01-08, 2008.

VIANNA, L. S.; SILVA, K. G.; BERTOSSI, A. P. A.; MENDES, T. N.; XAVIER, T. M. T. Análise da qualidade da água para fins de irrigação na microbacia do Rio Alegre, ES. Enciclopédia Biosfera, Centro Científico Conhecer - Goiânia, v.7, n.12 p.1-8. 2011. 